\title{
College of Sexual and Relationship Therapists (COSRT)
}

\section{Susan Quilliam}

Writer, Broadcaster, Consultant and Trainer, Cambridge, UK

\section{Correspondence to} Ms Susan Quilliam; susan@susanquilliam.com http://www.susanquilliam.com

Received 17 December 2012 Accepted 17 December 2012 Published Online First

5 February 2013
To cite: Quilliam S. Journal of Family Planning and Reproductive Health Care 2013;39:147-148.

\section{WHO ARE YOU?}

The College of Sexual and Relationship Therapists (COSRT) is the UK's leading membership organisation for therapists specialising in sexual and relationship issues.

Founded more than 30 years ago (and originally called the British Association for Sexual and Relationship Therapy), we now have a membership of over 800 , of which the majority are professional therapists. Our members come from a range of different backgrounds and disciplines and can be found anywhere in the country.

COSRT supports its members through conferences, seminars, professional networking opportunities, a regular newsletter and our own international, peer-reviewed journal. We provide a 'find a therapist' service for members of the public who feel they need professional support with their relationship issues. Finally, we set and maintain standards for the profession through our accreditation of members, approval of training courses and our Code of Ethics.

COSRT is run by a very small team of staff, whose work is supported by member volunteers and run by our professional standards and other committees. We were well ahead of the current fashion for 'virtual offices' and meetings held electronically - COSRT has no permanent office space and all our team members work from their own homes.

\section{DESCRIBE A TYPICAL CLIENT/USER}

There's probably no such thing as a typical COSRT member. Our members practise couple, relationship or sexual therapy in a variety of settings, either as individual therapists or part of a group practice. We also have affiliate members who work in many other disciplines such as social work and the health service (e.g. nurses, doctors, health visitors and midwives) or who work in family planning and infertility clinics.
It's just as hard to define the members of the public who visit our website. They could be looking for help to find a therapist, be in need of advice about a specific problem, or just seeking guidance on keeping their relationships in good working order.

\section{HOW DO YOU GET CLIENTS?}

Our members come to us by a variety of routes. Some join after finding our website (http://www.cosrt.org.uk). Many others join after attending a training day or conference we have organised, by reading our journal, or after a recommendation from a colleague. A typical route is through attending one of the courses approved by COSRT to qualify therapists in the field. Members of the public generally find us by searching for help online, though they can also be referred to us by their general practitioner or other health care providers.

\section{DO YOU RUN ANY SPECIAL EVENTS?}

We organise two major conferences and a number of smaller Continuing Professional Development (CPD) training events each year. Most of these events are open to nonmembers who want to develop their understanding of a subject, as well as to COSRT members.

There are details of all of our forthcoming events and how to book for them on our website (http://www.cosrt.org.uk). Training already arranged for 2013 includes sessions on Working with Sexualised Trauma, Working with Clients Affected by Female Genital Mutilation, Mindfulness, The World of Sexual Healing, Sensate Focus, and Asexuality.

\section{HOW DO YOU FIT (OR COMPETE) WITH OTHER SIMILAR \\ ORGANISATIONS IN THE FIELD?}

COSRT is the only UK-based membership organisation that specialises in sexual as well as relationship therapy. 
Some of our members belong both to COSRT and another organisation - such as the British Association for Counselling \& Psychotherapy (BACP) or UKCP (UK Council for Psychotherapy) or work with Relate. We are trying to develop our international links through our international journal, Sex and Relationship Therapy, and welcome international members. We're happy to share our expertise!

\section{DO YOU GIVE COMMENTS TO THE PRESS? WHAT ARE THE KEY ISSUES YOU COMMENT ON?}

Because of the kind of work our members do and the importance of maintaining confidentiality about client details and stories, commenting to the press can be a difficult issue for us.

However, we are trying to find ways in which we can take more of a part in public debate. There are so many issues in the public eye that involve sexual relations and sexuality in one form or another - from the revelations about Jimmy Savile, to debates about making sex education in schools compulsory - that having an informed voice taking part in the debate could be really helpful. It's a challenge we're very aware of!

\section{WHAT'S BEEN YOUR BIGGEST PROBLEM?}

There's still a great deal of misinformation about the work that we do and a widespread lack of understanding of what sex and relationship therapy is all about. Quite often the biggest task is to get people to engage with the subject at all.

\section{WHAT'S BEEN YOUR BIGGEST TRIUMPH OVER THE YEARS?}

We're proudest of the way we have raised the debate on sexual issues with different professional groups, and of being able to share training in sex and relationship issues with people from such a wide range of other disciplines.

\section{WHAT ARE YOUR MOST EXCITING PLANS/ BIGGEST HOPES FOR THE FUTURE?}

We have an ambitious development plan for the next few years. We want to increase our membership, improve the services we offer to our members, and develop partnerships with other organisations whose work touches on issues around sex, but who may not have our expertise.

For example, it would be great to work with some specialist health charities whose clients find that they are facing difficulties with their sexual relationship as a result of a medical condition. We want to raise awareness of signposting this at the point of diagnosis. Many medics need to focus on treatment and survival, and forget the impact that illness can have on a patient's relationship and sex life. Early signposting can help stop problems becoming entrenched for patients and their partners.

We're also really pleased with the plans for our new website, which is being overhauled to give much more help to members of the public, and clearer, better information for the profession. Come and have a look!

\section{HOW CAN JOURNAL READERS AND THEIR PATIENTS CONTACT YOU?}

We're very happy to hear from anyone who might be interested in joining COSRT, or who just wants to know more about us or needs some advice on a topic related to our work. Our contact details are provided in the Further Information box below, and our Administrator, Anne, will put you in touch with someone you can talk to.

\section{FURTHER INFORMATION}

Who: College of Sexual and Relationship Therapists (COSRT) Contact: Anne (Administrator). Tel: +44 (0)20 85432707.

E-mail: info@cosrt.org.uk

Website: http://www.cosrt.org.uk

Competing interests None.

Provenance and peer review Not commissioned; internally peer reviewed.

Editor's note This article is one in a series of occasional articles on key health organisations worldwide. The Journal would be pleased to hear from other organisations, particularly those based outside the UK, that would like to be similarly profiled.

\section{Access to Online First Journal Articles, Blogs and Podcasts via the Faculty Website}

Faculty members can easily access journal articles that have been recently published online via the Online First facility at http://www.fsrh.org/pages/the_journal.asp before they appear in a print issue of the Journal. They can also access the latest blogs and online podcasts from this link. 